\title{
Congenital glioblastoma coexisting with vascular developmental anomaly
}

\author{
Milena Laure-Kamionowska ${ }^{1}$, Krystyna Szymanska ${ }^{1,2}$, Monika Biekiesinska-Figatowska ${ }^{3}$, Barbara Gierowska-Bogusz ${ }^{4}$, \\ Elżbieta Michalak ${ }^{5}$, Teresa Klepacka ${ }^{5}$ \\ ${ }^{1}$ Department of Experimental and Clinical Neuropathology, Mossakowski Medical Research Centre, Polish Academy of Sciences, \\ ${ }^{2}$ Department of Child Psychiatry, Medical University of Warsaw, ${ }^{3}$ Department of Diagnostic Imaging, Institute of Mother and Child, \\ ${ }^{4}$ The Neonatology and Neonatal Intensive Care Clinic, Institute of Mother and Child, ${ }^{5}$ Department of Pathology, Institute of Mother \\ and Child, Warsaw, Poland
}

\begin{abstract}
Congenital central nervous tumours form a unique group of neoplasms. They are different from other tumour groups not only due to the onset time but also to their histopathology, anatomic location, and biologic behaviour. Congenital glioblastoma is one of the rarest types of congenital brain tumours and is uncommon in the prenatal period. We report a rare case of congenital glioblastoma detected prenatally by ultrasound examination and magnetic resonance imaging at 26 gestational weeks. Based on MRI findings and consultation of a team of specialists, pregnancy was terminated at 28 weeks. The newborn presented hydrops foetal. The child died shortly after birth due to cardiorespiratory insufficiency. At autopsy a large tumour with a spongy-like appearance was found. The tumour involved nearly the whole right cerebral hemisphere and led to marked hydrocephalus. In the histological and immunohistochemical examination, the tumour presented features of glioblastoma. Neoplastic cells were immunopositive for GFAP, S-100 protein and negative for neuronal markers. Frequent mitoses and high MIB-1 labelling index were seen in the tumour areas. The coexistence of tumour and vascular developmental anomaly was stated. The conglomerates of numerous, distended, thin-walled foetal-like blood vessels were located beside the tumour tissue, which presented disturbance in differentiation and maturation of the vascular net. Such coexistence of malignant glioma with vascular developmental anomaly is unique.
\end{abstract}

Key words: congenital brain tumour, congenital glioblastoma, vascular developmental anomaly, persistent foetal-like vessels.

\section{Introduction}

Congenital central nervous tumours form a unique group of neoplasms $[14,15,26]$. They are different from other tumour groups not only due to the onset time but also to their histopathology, anato- mic location, and biologic behaviour. Congenital brain tumours account for less than $2 \%$ of all paediatric tumours. Congenital glioblastoma (cGBM) is one of the rarest types of congenital brain tumour, with less than 50 cases reported in the literature [13] and is uncommon in the prenatal period 
$[17,23,33,34]$. Screening methods have improved significantly prenatal detection of tumours [28].

Gliomas are the most common primary brain tumours and they are characterized by different molecular pathways and biological behaviour in children and adults $[19,29,35]$. Molecular alterations in adult GBM include abnormalities associated with the epidermal growth factor receptor [1,21], platelet-derived growth factor receptor, phosphatase and tensin homologue, INK4a/ARF, isocitrate dehydrogenase and TP53 [6,16,19].

Congenital glioblastomas are genetically distinct from adult and TP53 pathway dysregulation is important in their tumourigenesis [7]. Unique molecular features of CGBM include also overexpression of multiple genes involved in glucose metabolism and tissue hypoxia [25].

We present a rare case of congenital glioblastoma, detected prenatally, coexisting with vascular developmental anomaly.

\section{Case report}

A 34-year-old woman, gravida 4, para 2, 2 spontaneous abortions. The family history was unremark- able. Routine foetal ultrasonography was done at 24 weeks of gestation. Ultrasonography of the foetus revealed a large mass of rapidly growing brain tumour with hydrocephalus. Examination of the intracranial structures revealed the hypervascular mass measuring $71.0 \times 68.0 \mathrm{~mm}$ with irregular outlines, occupying the entire right cerebral hemisphere. Asymmetrical ventricular enlargement was stated. Magnetic resonance imaging (MRI) of the foetus was performed at the gestational age of 26 weeks. It revealed a pathological mass in the right cerebral hemisphere. It was heterogeneous, mostly solid but with areas of necrosis and haemorrhage (calcifications within the mass seemed less probable) (Fig. 1A). It measured approximately 66 (anterior-posterior) × 61 (right-left) $\times 56$ (cranio-caudal) $\mathrm{mm}$. There was a shift of the midline structures to the left by $14 \mathrm{~mm}$ and hydrocephalus. There was only a very narrow band of the preserved brain tissue around the enlarged left lateral ventricle, mainly in the frontal region. On the right, the cranium was filled with a large mass lesion and only a part of the frontal lobe was preserved around the widened frontal horn. The MRI diagnosis of brain tumour was suggested. The lesion was accompanied by the widened dural sinuses, internal jugular veins, superior
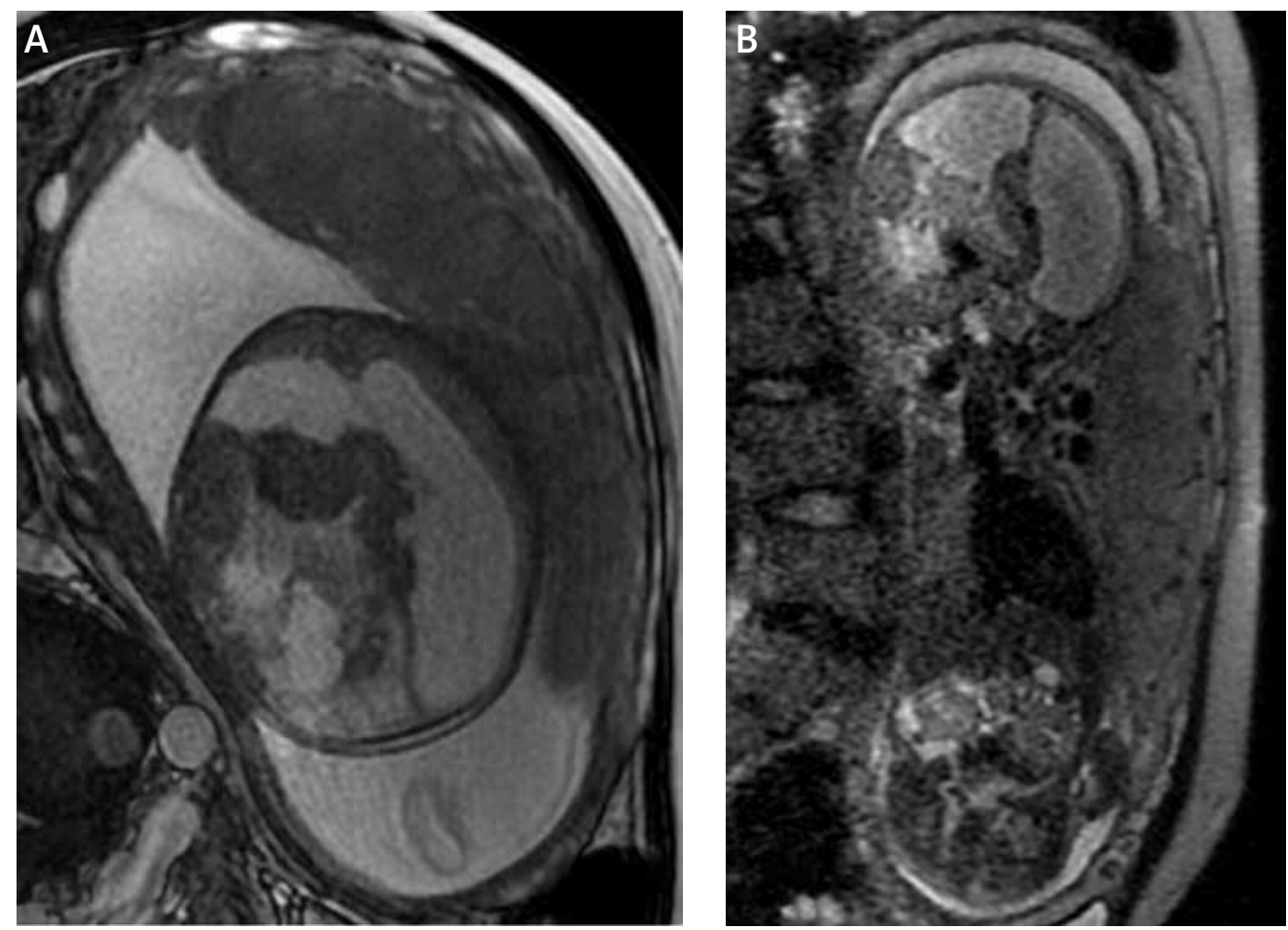

Fig. 1. Foetal MRI. A) Heterogeneous mass in the right hemisphere with midline shift and hydrocephalus. FIESTA/2D sequence, axial plane. B) Tumour mass, widened superior vena cava and cardiomegaly. SSFSE/ T2-weighted image, coronal plane. 
vena cava and enlarged heart (Fig. 1B) which showed significant hemodynamic instability.

Based on the MR findings and consultation with obstetricians, paediatric neurosurgeons and neonatal intensive care unit team, the decision to terminate pregnancy was made because of rapidly growing and devastating brain tumour that was suspected to be malignant.

At 28 weeks of pregnancy, a female newborn was delivered by caesarean section. The newborn measured $43 \mathrm{~cm}$ and weighed $2680 \mathrm{~g}$ (> 95 th percentile) and presented foetal hydrops. The head circumference was $40 \mathrm{~cm}$ (>97 $97^{\text {th }}$ percentile), chest circumference $34 \mathrm{~cm}$. Apgar score was 1 (heart rate below 100/min). The child died after 90 minutes.

\section{Material and methods}

A post-mortem examination was done. The brain was fixed in $10 \%$ formalin. Specimens from the cerebral hemispheres, brain stem and cerebellum were taken, embedded in paraffin and routinely stained with haematoxylin-eosin and cresyl violet. Immunohistochemical studies were performed on paraffin-embedded specimens using the standard avidin-biotin-peroxidase complex method with antibodies against glial fibrillary acidic protein (GFAP), S-100 protein, synaptophysin, CD31, CD34, SMA, p53 and Ki67 (all reagents from Dako).

\section{Neuropathological examination}

Macroscopic evaluation showed a large tumour with a sponge-like appearance which involved nearly the whole right cerebral hemisphere, passed across the median line structures and led to marked hydrocephalus by secondary aqueductal stenosis. The tumour was poorly demarcated from the surrounding tissue, infiltrating almost totally the white matter of the frontal, parietal, and temporal lobes. The tumour was soft, spongy, gray-black with haemorrhages and highly vascular areas.

Microscopically, the tumour involved cerebral lobes of the right hemisphere and presented an infiltrative growth pattern in the white matter adjacent to the lateral and third ventricles. The interface between the tumour and adjacent brain parenchyma demonstrated a diffusely infiltrative border. Focal perivascular cuffings of neoplastic cells were seen in the surrounding tissue. The widespread infiltration was seen through the germinal matrix nests and cerebral cortex. In some areas, the mixture of germinal and tumour cells with small necrotic foci and haemorrhages was evident (Fig. 2). The other parts of the cerebral cortex was properly formed and demonstrated widespread neuronal damage.

The main highly cellular tumour mass was predominantly composed of small monomorphic cells with round or ovoid nuclei and minimal discernable cytoplasm (Figs. 3A-B). Some neoplastic cells displayed the prominent eosinophilic cytoplasm or gemistocytic features with mild nuclear hyperchromasia. The tumour was mitotically active and Ki 67 labelling index was high (Figs. 3C-D). Tumour cells exhibited glial fibrillary acidic protein (GFAP)-positivity (Fig. 3E), immunoreactions for S-100 protein. This part of densely cellular tumour was highly vascular (Figs. 3A, 3F) and demonstrated numerous small foci of necrosis surrounded by radially-oriented neoplastic cells forming "pseudopalisading" (Fig. 3G). The capillaries exhibited prominent endothelial proliferation (Fig. 4A). The predominant form of vascular proliferation was presented as glomeruloid structures or ramified new vessels. The multilayered endothelial cells seen around the lumen of vessels exhibited CD31 positivity (Fig. 4B). The aSMA positive pericytes of irregular shape and evident cytoplasmic processes were arranged circumferentially (Figs. 4C-D).

Moreover, the conglomerates of distended, thinwalled foetal-like blood vessels were found within the neoplastic tissue (Fig. 5) or outside the main tumour mass (Fig. 4E). Immature blood vessels lined by a single layer of flat endothelium formed a net of

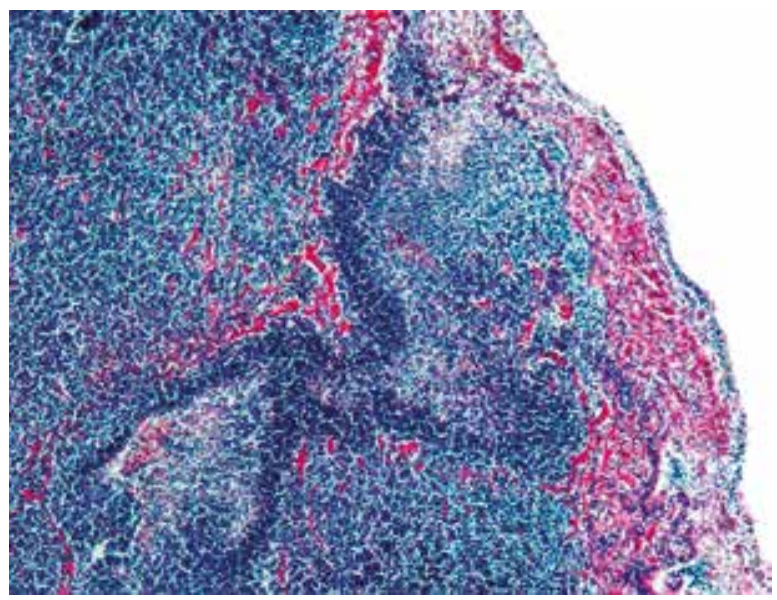

Fig. 2. Mixture of germinal and tumour cells in the periventricular germinal nests. Cresyl violet. Orig. magn. $\times 40$. 

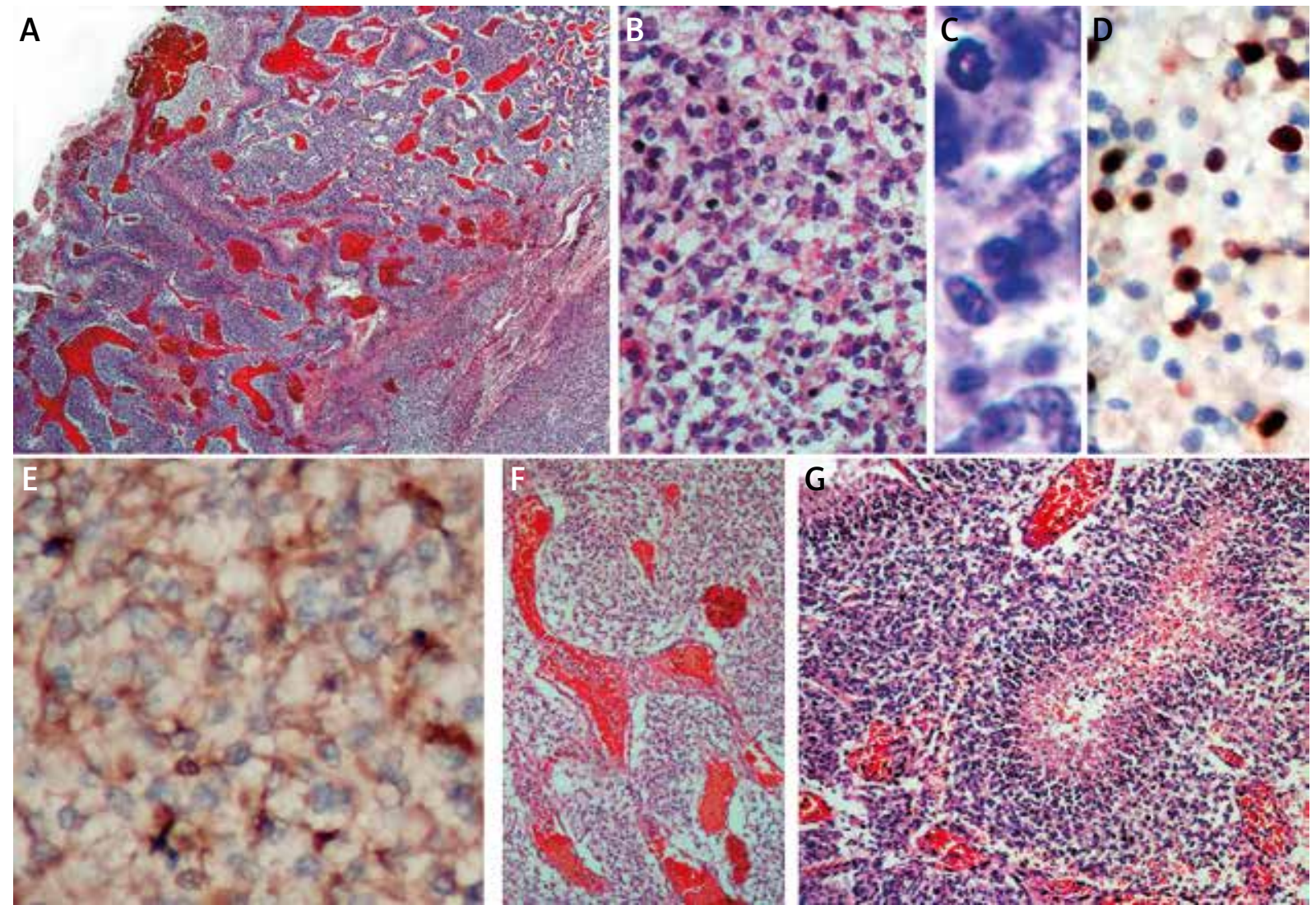

Fig. 3. The morphological features of the tumour. A) Markedly hypercellular and highly vascular tumour. Orig. magn. $\times 40$. B) Small, monomorphic cells with minimal discernible cytoplasm. Orig. magn. $\times 200$. C) Neoplastic cells with ovoid nuclei, mitotic figure. Orig. magn. $\times 400$. D) High Ki67 labelling index. Orig. magn. $\times 400$. E) Thin, GFAP-positive cytoplasmic processes forming a fibrillary background. Orig. magn. $\times 400$. F) Vessels among neoplastic tissue. Orig. magn. $\times 200$. G) Focal areas of pseudopalisading necrosis. Orig. magn. $\times 200$.

CD31-positive hemorrhagic vascular channels (Fig. 4F). The SMA positive pericytes located around the vessels were flattened and devoid of processes (Fig. 4G).

The final diagnosis of congenital glioblastoma with vascular developmental anomaly was established.

\section{Discussion}

The histopathological diagnosis of congenital glioblastoma was based on its typical morphology and immunohistochemical findings. The morphological picture of tumour fulfilled the World Health Organization criteria for diagnosis of GBM, based on the presence of necrosis, pseudopalisading, mitotic figures and microvascular proliferation [24]. A monomorphic cell population characterized predominantly by small, round to slightly elongated, densely-packed cells with mildly hyperchromatic nuclei, high nuclear/ cytoplasmic ratios suggests a particular type of GBM called small cell glioblastoma [24].

The tumour was detected prenatally by ultrasonography. The foetal MRI is used to confirm, verify or complete prenatal sonographic diagnosis of CNS abnormalities. In the present case, MR images suggested the malignant brain tumour. So far there have been four congenital brain tumours established in the material of the Department of Diagnostic Imaging of the Institute of Mother and Child: teratoma, desmoplastic infantile astrocytoma (DIA), choroid plexus carcinoma (CPC) and craniopharyngioma [5]. The CPC images had been quite similar to the MRI images of the presented case. The diagnosis of GBM was not taken into account prenatally because of its rarity.

The development of foetal MRI allows to establish the early diagnosis of congenital tumours. To 

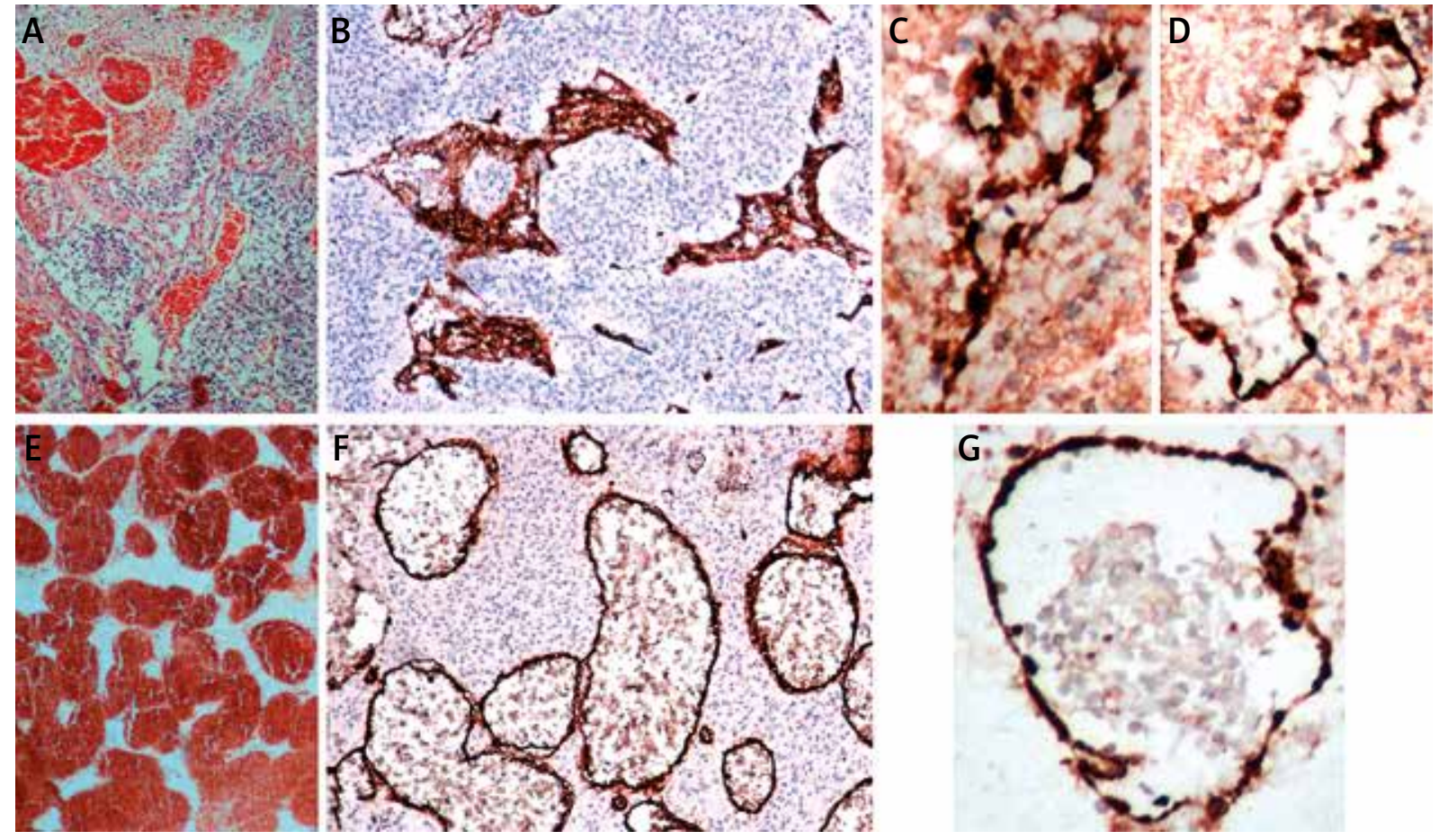

Fig. 4. Blood vessels in the tumour tissue and in the vascular anomaly. A) Tumoural microvascular hyperplasia. B) CD31-positive proliferating endothelial cells forming multiple layers. Orig. magn. $\times 200$. C-D) Irregularly shaped $\alpha S M A$ protein positive pericytes with prominent cytoplasmic processes. Orig. magn. $\times 400$. E) Numerous, distended, thin-walled foetal-like vessels of the vascular anomaly. Orig. magn. $\times 200$. F) Vessel anomaly-single layer of flat, CD31 positive endothelial cells. G) Small, flattened, devoid of processes $\alpha S M A$ positive pericytes in the vascular anomaly. Orig. magn. $\times 400$.

our knowledge, the described case is the youngest reported so far in the literature. In the majority of reported cases, the gestational age at diagnosis of the tumour was more than 32 weeks $[13,23,31,32,37]$. In this case, the tumour was detected at 24 week of pregnancy but its growth had begun earlier. The progression of tumour growth occurred very rapidly. During normal brain development the neuronal cells migrate from the germinal matrix, which is a highly vascular source of neuronal glial precursor cells, through the white matter to the cerebral cortex. Migration to the neocortex starts at the end of the second month of gestation. Two great consecutive waves of cells migration from the germinal matrix to the cortex appear during the third and fourth month of gestation. Then, the activity of migration diminishes and is nearly completed by the middle of the seventh gestational month. The affected course of normal neuronal migration resulted in cortical malformations or heterotopias [8,22]. In the present case, the tumour most probably grew after the period of intense neuronal migration because there were no cortical anomalies and arrest of neurons in the white matter.

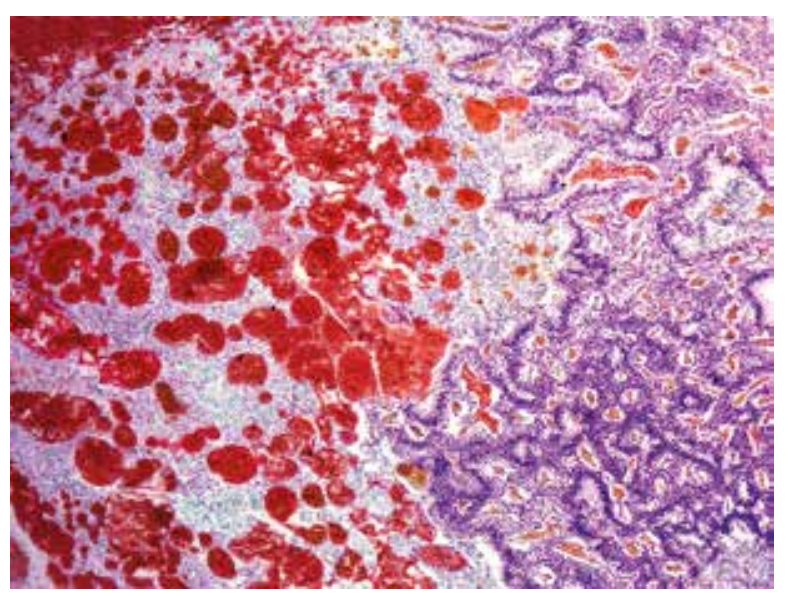

Fig. 5. The conglomerates of numerous, distended thin-walled vessels accompanying the neoplastic tissue. Haematoxylin eosin. Orig. magn. $\times 40$. 
In the presented case, the main tumour mass was accompanied by the rich network of vascular channels embedded in scarce, loose tissue. This abundant plexus of vessels was similar to the thin-walled, non-differentiated foetal-like vessels observed in the early embryonic stages of development. During normal development of vascularisation, the primitive endothelial cells constitute the primary primitive vascular plexus. The primary plexus subsequently develops into a complex organized vascular network due to endothelial proliferation (angiogenesis). In the final process of vascular development, the mesenchymal cells differentiate into pericytes, which surround blood vessels and make them mature and stable. Pericytes are engaged in different stages of normal angiogenesis including initiation, sprout extension, migration and maturation of vessels $[3,17]$. Some vessels regress and the rest differentiates and matures to a genetically-coded pattern of brain vascularisation. If regression is not complete, the persistent vessels, often not fully differentiated, occur as angiomas [30]. Neonatal angiomas are composed of numerous thin-walled vessels, lined by a single layer of flat endothelium and separated by variable amounts of loose connective tissue [9]. Despite the congenital origin of angiomas, they rarely occur in the neonatal and prenatal period. Only a few such cases have been reported in the literature $[12,20,38]$. Udayakumaran and co-workers found 21 cases of cavernous angioma in the neonatal and prenatal period described in the English literature [36]. In the presented case, the conglomerates of vessels in the vicinity of tumour may represent the prenatal angioma, however it is also possible that the vascular anomaly corresponds to the preserved primitive foetal vessels. Persistent foetal primitive vascular plexus consists of abundant sinusoid capillaries forming a dense plexus in the leptomeninges covering nervous tissue. The foetal pattern of vessels normally persists beyond the period of primary plexus formation [9]. Thus, the primitive foetal-like vessels could be included into the infiltrating neoplastic tissue.

In adults, the primary brain tumours may be accompanied by vascular malformations [27] and such rare coincidence involves mostly gliomas and meningiomas $[10,11]$. The pathogenetic suggestions consider such angiogliomatic lesions as a result of reactive astroglial neoplastic proliferation secondary to the pre-existing vascular malformation. Only a few cases concerning coexistence of tumour and aneurysm have been reported in infantile cases $[2,4]$. The coexistence of vascular anomaly and congenital glioblastoma is unique and up to our knowledge has not been reported.

\section{References}

1. Adamek A, Zazula M, Radwańska E, Grzywna E, Sińczak-Kuta A, Moskała M. Co-occurrence of MGMT gene promoter methylation and amplification of EGFR in glioblastoma. Wspolczesna Onkol 2011; 15: 362-366.

2. Belle F, Lückers O, Otto B, Hoyoux C, Hans P, Born JD. Arterial aneurysm within a tumor in a pediatric patient. Neurochirurgie 2002; 48: 30-34.

3. Bergers $G$, Song S. The role of pericytes in blood-vessel formation and maintenance. Neuro Oncol 2005; 7: 452-464.

4. Boop FA, Chadduck WM, Sawyer J, Husain M. Congenital aneurysmal hemorrhage and astrocytoma in an infant. Pediatr Neurosurg 1991-1992; 17: 44-47.

5. Biekiesinska-Figatowska M, Jurkiewicz E, Duczkowski M, Duczkowska A, Romaniuk-Doroszewska A, Brągoszewska H, Ceran A. Congenital CNS tumors diagnosed on prenatal MRI. Neuroradiol J 2011; 24: 477-481.

6. Birner P, Toumangelova-Uzeir K, Natchev S, Guentchev M. Expression of mutated isocitrate dehydrogenase-1 in gliomas is associated with p53 and EGFR expression. Folia Neuropathol 2011; 49: 88-93.

7. Brat DJ, Shehata BM, Castellano-Sanchez AA, Hawkins C, Yost RB, Greco C, Mazewski C, Janss A, Ohgaki H, Perry A. Congenital glioblastoma: A clinicopathologic and genetic analysis. Brain Pathol 2007; 17: 276-281.

8. Dambska M, Wisniewski KE. Normal and pathologic development of the human brain and spinal cord. John Libbey \& Company Ltd 1999; pp. 117-131.

9. Friede RI. Dysplasias of cerebral vessels. In: Developmental Neuropathology. Springer Verlag, Berlin Heidelberg 1989; pp. 395-402.

10. Gazzeri R, De Bonis C, Carotenuto V, Catapano D, d'Angelo V, Galarza M. Association between cavernous angioma and cerebral glioma. Report of two cases and literature review of so-called angiogliomas. Neurocirugia 2011; 22: 562-566.

11. Gmeiner M, Sonnberger M, Wurm G, Weis S. Glioblastoma with the appearance of arteriovenous malformation: Pitfalls in diagnosis. Clin Neurol Neurosurg 2013; 115: 501-506.

12. Hashimoto H, Sakaki T, Ishida Y, Shimokawara T. Fetal cavernous angioma. Case report. Neurol Med Chir (Tokyo) 1997; 37: 346349

13. Hou LC, Bababeygy SR, Sarkissian V, Fisher PG, Vogel H, Barnes P, Huhn SL. Congenital glioblastoma multiforme: case report and review of the literature. Pediatr Neurosurg 2008; 44: 304-312.

14. Isaacs H. I .Perinatal brain tumors: A review of 250 cases. Pediatr Neurol 2002; 27: 249-261.

15. Isaacs H. II. Perinatal brain tumors: a review of 250 cases. Pediatr Neurol 2002; 27: 333-342.

16. Kahlert UD, Bender NO, Maciaczyk D, Bogiel T, Bar EE, Eberhart CG, Nikkhah G, Maciaczyk J. CD133/CD15 defines distinct 
cell subpopulations with differential in vitro clonogenic activity and stem cell-related gene expression profile in in vitro propagated glioblastoma multiforme-derived cell line with a PNETlike component. Folia Neuropathol 2012; 50: 357-368.

17. Kamimoto M, Sameshima H, Uetsuhara K, Tomosugi T, Matsuda Y, Ibara S, Sueyoshi K. Fetal glioblastoma:rapid growth during the third trimester. Fetal Diagn Ther 1998; 13: 339-342.

18. Kamouchi M, Ago T, Kitazano T. Brain pericytes: Emerging concepts and functional roles in brain homestasis. Cell Mol Neurobiol 2011; 31: 175-193.

19. Karsy M, Gelbman M, Shah P, Balumbu O, Moy F, Arslan E. Established and emerging variants of glioblastoma multiforme: review of morphological and molecular features. Folia Neuropathol 2012; 50: 301-321.

20. Kon T, Mori H, Hasegawa K, Nishiyama K, Tanaka R, Takahashi H. Neonatal cavernous angioma located in the basal ganglia with profuse intraoperative bleeding. Childs Nerv Syst 2007; 23: 449-453.

21. Larysz D, Kula D, Kowal M, Rudnik A, Jarząb M, Blamek S, Bierzyńska-Macyszyn G, Kowalska M, Bażowski P, Jarząb B. Epidermal growth factor receptor gene expression in high grade gliomas. Folia Neuropathol 2011; 49: 28-38.

22. Laure-Kamionowska M, Maślińska D. Cerebellar cortical neurons misplaced in the white matter due to disturbed migration during development of human brain. Folia Neuropathol 2011; 49: 282-294.

23. Lee DY, Kim YM, Yoo SJ, Cho BK, Chi JG, Kim IO, Wang KC. Congenital glioblastoma diagnosed by fetal sonography. Childs Nerv Syst 1999; 15: 197-201.

24. Louis DN, Ohgaki H, Wiestler OD, Cavenee WK, Burger PC, Jouvet $A$, Scheithauer BW, Kleihues P. The WHO classification of tumors of the central nervous system. Acta Neuropathol 2007; 114: 97-109.

25. Macy ME, Birks DK, Barton VN, Chan MH, Donson AM, Kleinschmidt-DeMasters BK, Bemis LT, Handler MH, Foreman NK. Clinical and molecular characteristics of congenital glioblastoma. Neuro Oncol 2012; 14: 931-941.

26. Mazewski CM, Hudgins RJ, Reisner A, Geyer JR. Neonatal brain tumors: a review. Semin Perinatol 1999; 23: 286-298.

27. Naganska E, Matyja E, Pucko E, Zabek M. The coexistence of pleomorphic xantoastrocytoma and arteriovenous malformation. A case report. Folia Neuropathol 2013; 51: 269-274.

28. Parmar HA, Pruthi S, Ibrahim M, Ghandi D. Imaging of congenital brain tumors. Semin Ultrasound CT MRI 2011; 32: 578-589.

29. Preusser M, Haberler C, Hainfellner J. Malignant glioma: neuropathology and neurobiology. Wien Med Wochenschr 2006 156/11-12: 332-337.

30. Rafalowska J. Developmental failures of blood vessels within central nervous system. Folia Neuropathol 1995; 33: 201-206.

31. Seker A, Ozek MM. Congenital glioblastoma multiforme. A case report and review of the literature. J Neurosurg 2006; 105: 473-479.

32. Sell M, Huber-Schumacher S, van Landeghem FK. Congenital glioblastoma multiforme with abnormal vascularity presenting as intracranial hemorrhage in prenatal ultrasound. Childs Nerv Syst 2006; 22: 729-733.

33. Shimamura N, Asano K, Ogane K, Yagihashi A, Ohkuma H, Suzuki S. A case of definitely congenital glioblastoma manifested by intratumoral hemorrhage. Childs Nerv Syst 2003; 19: 778-781.
34. Soler-Ferrero I, Hidalgo-Mora JJ, Vila-Vives JM, Baamonde-Vidarte A, Perales-Marin A. Diagnosis of foetal glioblastoma multiforme with massive brain haemorrhage. Rev Neurol 2012; 54: 189-191.

35. Soni D, King J, Kaye AH, Hovens C. Genetics of glioblastoma multiforme: mitogenic signaling and cell cycle pathways converge. J Clin Neurosci 2005; 12: 1-5.

36. Udayakumaran S, Paraskevopoulos D, Cagnano E, Roth J, Constantini S. Spontaneous bleeding into a suprasellar cavernous angioma of a neonate: case report and literature review. Childs Nerv Syst 2011; 27: 303-311.

37. Winters J, Wilson D, Davis DG. Congenital glioblastoma multiforme: a report of three cases and a review of the literature. J Neurol Sci 2001; 188: 13-19.

38. Yang CY, Hsu JF, Lin KL, Jung SM, Lien R, Chang YL. An extra-axial hemangioma mimicking a large prenatal brain tumor. Brain Dev 2010; 32: 883-886. 